\title{
Comparative Pharmacokinetic Study between Metformin Alone and Combined with Orlistat in Healthy Mexican Volunteers
}

\author{
Noemí Santos-Caballero ${ }^{1}$, Francisco Javier Flores-Murrieta ${ }^{2,3}$ \\ ${ }^{1}$ Landsteiner Scientific, S.A. de C.V., México, D.F., Mexico; ${ }^{2}$ Sección de Estudios de Posgrado e Investigación, Escuela Superior de \\ Medicina, Instituto Politécnico Nacional, México, D.F., Mexico; ${ }^{3}$ Unidad de Investigación en Farmacología, Insituto Nacional de \\ Enfermedades Respiratorias "Ismael Cosio Villegas", México, D.F., Mexico. \\ Email: nsantos@1andsteiner.com,nsantoscaballero@gmail.com
}

Received March $8^{\text {th }}, 2012$; revised April 20 $0^{\text {th }}, 2012$; accepted May $8^{\text {th }}, 2012$

\begin{abstract}
Traditional treatment of type 2 diabetes mellitus (T2DM) has focused on correcting hyperglycemia. However, T2DM is almost always accompanied by other conditions and risk factors that affect its morbidity and mortality. Obesity represents one of the main risk factors associated in the T2DM and a modest weight loss around 5\% is linked with significant reduction in the blood glucose levels. The objective of this study was to compare the pharmacokinetic parameters between two formulations of metformin, alone or combined with orlistat, in healthy volunteers. A single-blinded, single dose, two-period, two-sequence, crossover, randomized and balanced study design with a 7-day washout period was performed in 26 Mexican volunteers. Plasma samples were collected over a 24-hour period after administration of 500 $\mathrm{mg}$ metformin alone or combined with $60 \mathrm{mg}$ orlistat in each period. A validated high-performance liquid chromatography coupled with an ultraviolet detector was used to analyze metformin concentration in plasma. Bioequivalence between metformin alone and metformin combined with orlistat was determined when the ratio for the $90 \%$ confidence intervals $(\mathrm{CI})$ of area under the curve $\left(\mathrm{AUC}_{24 \mathrm{~h}}\right)$ and maximum concentration $\left(\mathrm{C}_{\max }\right)$ of the two formulations were within $80 \%$ and $125 \%$. In the current study, the mean \pm standard deviation (SD) of $\mathrm{C}_{\max }, \mathrm{AUC}_{24 \mathrm{~h}}$ and $\mathrm{AUC}_{\infty}$ of the formulation containing only metformin were $1.39 \pm 0.44 \mu \mathrm{g} / \mathrm{mL}, 7.59 \pm 3.17 \mu \mathrm{g} \cdot \mathrm{h} / \mathrm{mL}$ and $8.48 \pm 4.13 \mu \mathrm{g} \cdot \mathrm{h} / \mathrm{mL}$, respectively, while the mean $\pm \mathrm{SD}$ of $\mathrm{C}_{\max }, \mathrm{AUC}_{24 \mathrm{~h}}$ and $\mathrm{AUC}_{\infty}$ of the formulation containing metformin and orlistat were $1.38 \pm 0.48$ $\mu \mathrm{g} / \mathrm{mL}, 7.80 \pm 2.83 \mu \mathrm{g} \cdot \mathrm{h} / \mathrm{mL}$ and $9.13 \pm 4.29 \mu \mathrm{g} \cdot \mathrm{h} / \mathrm{mL}$, respectively. The parametric $90 \% \mathrm{CI}$ for $\mathrm{C}_{\max }$ and $\mathrm{AUC}_{24 \mathrm{~h}}$ were 87.5 - 109.3 and $88.7-124.7$, respectively. These results suggest that both formulations are bioequivalent and there is not pharmacokinetic interaction between metformin and orlistat.
\end{abstract}

Keywords: Metformin; Orlistat; Diabetes; Obesity; Bioequivalence; Pharmacokinetics

\section{Introduction}

Diabetes is a chronic disease, which occurs when the pancreas does not produce enough insulin, or when the body cannot effectively use the insulin it produces. This leads to hyperglycemia; altered metabolism of lipids, carbohydrates, and proteins; and elevated risk of vascular complications. Type 2 diabetes mellitus (T2DM), formerly called non-insulin-dependent or adult-onset comprises $90 \%$ of people with diabetes around the world and it is global health problem. The World Health Organization publishes in its web page that 346 million people worldwide have diabetes and 3.4 million people died from consequences of high blood sugar in 2004 [1]. A recent study performed taking information from 91 countries reported that prevalence of diabetes among adults was $6.4 \%$, affecting 285 million adults, in 2010, and it will increase to $7.7 \%$ and 439 million adults by 2030 . In Mexico, the prevalence of diabetes among adults aged 20 79 years was estimated in $10.1 \%$ in 2010 and $13.3 \%$ in 2030 [2]. In addition, this condition leads causes of death in this country [3].

Interestingly, around $90 \%$ of cases of T2DM in Mexico can be attributed to the obesity and overweight. In fact, these two conditions have a very close connection that favors development of other chronic diseases, such as, breast and endometrial cancer, hypertension, stroke, among other diseases [3-7]. It is well known that a modest weight loss of $5 \%-10 \%$ is associated with significant reduction in blood sugar, lipid and blood pressure levels, as well as, other risk factors associated to this condition $[8,9]$. Furthermore, mortality risk increases with a body 
mass index $\geq 25 \mathrm{Kg} / \mathrm{m}^{2}$ [10]. For this reason, achieving a healthy weight and preventing weight gain are integral components of optimal diabetes management.

Traditional treatment of T2DM has focused on correcting hyperglycemia, antihyperglycaemic therapy is often initiated with metformin, which is a biguanide that reduces hepatic glucose production, increases glucose uptake and utilization in skeletal muscle and reduces carbohydrate absorption [11]. In addition, other nonglycaemic benefits ascribed to metformin include improvement in lipids with a modest weight loss or no weight gain, as well as, improvement in vascular reactivity, and endothelial and microvascular function [12, 13]. Metfomin is mainly absorbed in the small intestine, it has an oral bioavailability of $50 \%-60 \%$ under fasting conditions, its plasma protein binding is negligible, as reflected by its very high apparent volume of distribution. It is not metabolized by liver and $\sim 90 \%$ is excreted unchanged in the urine [14-19].

On the other hand, orlistat inhibits irreversibly gastric and pancreatic lipases preventing the breakdown of dietary fat to fatty acids and glycerols. It therefore decreases fat absorption and correspondingly increases faecal fat excretion up to some $30 \%$ of dietary fat. Together with a low-calorie diet in obese individuals, it produces a modest but consistent loss of weight [20,21]. In a study carried out in metformin-treated type 2 diabetic patients was added orlistat or placebo, after 1 year of treatment, orlistat increases weight loss and improving glycemic control, serum lipid levels, and blood pressure in obese patients with type 2 diabetes who are being treated with metformin [22]. In addition, combination metforminorlistat seems to be safety in acute and chronic treatment $[22,23]$. Orlistat has a bioavailability less than $5 \%$ when administered orally and it is only detectable in plasma by liquid chromatography-mass spectrometry or gas chromatography-mass spectrometry with a low detection limit. Virtually, $97 \%$ of orlistat is excreted in the faeces [24].

According to the evidence, it is suggested that combination metformin-orlistat might be a better treatment than individual administration of each drug since this treatment would improve adherence in obese patients with T2DM. In this regard, the objective of this study was to establish if orlistat coadministration could influence in the pharmacokinetics of metformin using a singleblinded, single dose, two-period, two-sequence, crossover, randomized and balanced study design with a 7-day washout period in Mexican volunteers.

\section{Subjects and Methods}

\subsection{Subjects}

Twenty-six healthy Mexican male and female volunteers between 22 and 40 years old with a body mass index < $28 \mathrm{Kg} / \mathrm{m}^{2}$, waist-to-height ratio $\leq 0.5$ and waist-hip ratio $<0.8$ for women and $<0.95$ for men were selected. All subjects signed an informed consent and were considered healthy as determined by screening tests including medical history, physical examination, electrocardiogram, hematic biometry, blood chemistry of 24 elements, drug abuse screening, general urine test, and hepatitis B and HIV tests. Vital signs were considered normal when blood pressure was $50-90 / 84-129 \mathrm{mmHg}$, heart rate was $50-100$ beats/min, breathing frequency was $14-25$ breaths $/ \mathrm{min}$ and otic temperature was $36^{\circ} \mathrm{C}-37.8^{\circ} \mathrm{C}$. The enrollment criteria also excluded subjects who had any prescription drug within 2 weeks prior to entering the study or who had consumed xanthines, alcohol, grilled food or grapefruit juice $72 \mathrm{~h}$ before the experiment; neither were included smokers, pregnant women and those with clinical history of hypersensitivity to drugs, food or environmental substances.

Experimental protocol was designed in accordance with the general ethical principles outlined in the Declaration of Helsinki. The protocol for this study, as well as the informed consent documents were thoroughly reviewed and approved by the Ethics Committee of Biomagno, S.A. de C. V. with the number 02-LTSF-03MTN/RLT-11 in April, 2011.

\subsection{Study Design}

The prospective and longitudinal study was conducted in a single-blinded, single dose, two-period, two-sequence, randomized, balanced and crossover design with a 1week washout period between treatments. A single dose of $500 \mathrm{mg}$ metformin or $500 \mathrm{mg}$ metformin plus $60 \mathrm{mg}$ orlistat was administered with $250-\mathrm{mL}$ water after 10 -h fasting. After dosing, serial blood samples were collected and vital signs were monitored during a period of $24 \mathrm{~h}$. Blood samples of $10 \mathrm{~mL}$ each were drawn at $0,0.25,0.5$, $0.75,1,1.25,1.5,1.75,2,3,4,6,8,12$ and $24 \mathrm{~h}$ after administration. Vital signs were measured at $0,1,2,3,4$, $6,8,12$ and $24 \mathrm{~h}$ after dosage. The subjects were housed for $36 \mathrm{~h}$ and were monitored for safety and adverse effects throughout the study. Volunteers received a diet calculated in $3000 \mathrm{cal} /$ day in each period.

\subsection{Metformin Formulations}

The commercially available reference product containing $500 \mathrm{mg}$ Metformin, Dabex ${ }^{\circledR}$ (Tablets, Merck S.A. de C.V.) from batch number M05013 (Formulation A, expiry date September, 2012) and the test product containing $500 \mathrm{mg}$ Metformin plus $60 \mathrm{mg}$ Orlistat (Capsules, Landsteiner S.A. de C.V.) from batch number LPD10H544 (Formulation B, expiry date September 2012) were 
used to carry out the current study.

\subsection{Analytical Method}

Sample preparation involved a separation with acetonitrile and dichloromethane. $0.5 \mathrm{~mL}$ of plasma was added $1.5 \mathrm{~mL}$ of acetonitrile. The mixture was vortex to maximum velocity for $30 \mathrm{~s}$ and centrifuged at $2000 \mathrm{rpm}$ for 10 min. Supernatant was mixed with $1.5 \mathrm{~mL}$ of dichloromethane and the new mixture was again vortex and centrifuged under the mentioned conditions in the previous step. Then, $50 \mu \mathrm{L}$ of supernatant were injected into the chromatographic system. A calibration curve includes the following concentration points: $0.05,0.1,0.2,0.5,1$ and $1.5 \mu \mathrm{g} / \mathrm{mL}$. The control samples were prepared with human plasma as biological matrix and appropriate amounts of drug to obtain concentrations of $0.15,0.4$ and 1.2 $\mu \mathrm{g} / \mathrm{mL}$.

High-performance liquid chromatography coupled to ultraviolet detector (HPLC/UV) was used to determine metformin plasma concentrations. The chromatographic system consisted of a high-resolution liquid chromatograph (Waters corporation) formed for a pump model 515 , an autosampler tray model 717 , a UV detector model 2487 and the software Empower 2.0 for data analysis. The separation was performed on a Resolve silica column of $150 \mathrm{~mm}$ of longitude, $3.9 \mathrm{~mm}$ of internal diameter and $90 \AA$ of particle size, using a mobile phase of acetonitrile/monobasic sodium phosphate $0.03 \mathrm{M}$ $(25: 75 \mathrm{v} / \mathrm{v})$ with a flow rate of $1.2 \mathrm{~mL} / \mathrm{min}$. The temperature of the autosampler tray was $4^{\circ} \mathrm{C}$ and the retention time of metformin was $3.5-4.5 \mathrm{~min}$. The absorbance was read at $234 \mathrm{~nm}$.

This method was developed and validated for specificity, sensitivity, linearity recovery, precision, accuracy, stability and robustness in our laboratory under NOM177-SSA1-1998 specifications. In this regard, metformin quantification was not interfered by acetaminophen, acetylsalicylic acid, salicylic acid, ibuprophen or heparin. Furthermore, the method was linear over a range of 0.05 $-1.5 \mu \mathrm{g} / \mathrm{mL}(\mathrm{r}=0.998)$, its quantification limit was 0.025 $\mu \mathrm{g} / \mathrm{mL}$ with $83.22 \%$ of metformin absolute recovery. Accuracy from control samples at $0.15,0.4$ and 1.2 $\mu \mathrm{g} / \mathrm{mL}$ concentrations was $8 \%, 3 \%$ and $1.75 \%$, respectively. The intra-assay coefficient of variation was $4.15 \%$, $3.28 \%$ and $2.40 \%$, respectively; and the inter-assay coefficient of variation was $3.46 \%, 10.25 \%$ and $6.75 \%$, respectively. No significant degradation of metformin during freezing and thawing cycles, short and long storage or processing conditions was noted.

\subsection{Pharmacokinetic and Statistical Analysis}

The sample size was calculated on the basis of a cross- over design with log-transformed data, considering an intra-individual variation coefficient of $20 \%$, a power of $80 \%$ and a significance level of $5 \%$, according to Chow and Wang [25]. Under these conditions, the calculated sample size was 18 volunteers; thus, taking into consideration potential withdrawals and dropouts, we enrolled 26 volunteers.

Curves of metformin plasma concentration versus time were constructed for each volunteer and for each formulation. The highest plasma concentration observed and the corresponding time was defined as the $\mathrm{C}_{\max }$ and $\mathrm{T}_{\max }$ values, respectively. The elimination rate constant $\left(\mathrm{K}_{\mathrm{e}}\right)$ was obtained by linear regression from the best-fit slope of the terminal log-linear decay in plasma concentrations versus time profile. The half-life $\left(\mathrm{t}_{1 / 2}\right)$ was obtained as $0.693 / \mathrm{K}_{\mathrm{e}}$. The area under the plasma concentration curve to the last quantifiable concentration $\left(\mathrm{C}_{\mathrm{t}}\right)$ at time $\mathrm{t}\left(\mathrm{AUC}_{0-\mathrm{t}}\right)$ was determined by linear trapezoidal integration. The AUC extrapolated to infinity $\left(\mathrm{AUC}_{0-\infty}\right)$ was calculated as $\mathrm{AUC}_{0-\mathrm{t}}+\mathrm{C}_{\mathrm{t}} / \mathrm{K}_{\mathrm{e}}$ [26]. The pharmacokinetics parameters were generated using the software WinNonlin Professional version 2.0 (Pharsight, Palo Alto, CA, EUA).

To evaluate bioequivalence, in order to establish no pharmacokinetic interaction, it was used an analysis of variance (ANOVA) for a crossover study design considering sequence, period, and treatment effects. The values of $\mathrm{AUC}$ and $\mathrm{C}_{\max }$ for each volunteer were transformed logarithmically and ratios between both formulations were calculated $\left[\log \left(\mathrm{AUC}_{24 \mathrm{~h}}^{\mathrm{B}} / \mathrm{AUC}_{24 \mathrm{~h}}^{\mathrm{A}}\right)\right.$

$\left.\log \left(\mathrm{C}_{\max }^{\mathrm{B}} / \mathrm{C}_{\max }^{\mathrm{A}}\right)\right]$. Then, it was obtained the mean and $90 \% \mathrm{CI}$ of the ratios of $\mathrm{AUC}_{24 \mathrm{~h}}$ and $\mathrm{C}_{\max }$. Bioequivalence between metformin alone and metformin combined with orlistat was determined when the $90 \%$ CI of these two parameters were within 0.8 and 1.25 and when $p \leq 0.05$ after two one-sided Schuirmann hypothesis test [27].

\section{Results}

After two treatment periods, 7 adverse effects were presented, 3 were observed with metformin alone and 4 with metfomin plus orlistat. The system more affected was digestive tract with 3 abdominal colic and 3 abdominal distensions; and the nervous system with 1 cephalea. In addition, women were more prone to present adverse effects ( 5 of 7 ) due to the treatment. All volunteers completed the study since adverse effects were mild Anthropometric characteristics of 26 Mexican volunteers finally included in this study ranged age between 21 and 40 years old, where $50 \%$ were women. In addition, range of body weight was between 49 and $81 \mathrm{Kg}$; height was between 1.47 and $1.81 \mathrm{~m}$ and range of body mass index was between 20.5 and $27.6 \mathrm{Kg} / \mathrm{m}^{2}$. Mean \pm standard deviation of these and other parameters are shown in the 
Table 1. In this regard, the obtained values by electrocardiogram, hematic biometry, blood chemistry, drug abuse screening, general urine test, and hepatitis B and HIV tests gave normal values for all volunteers (data not shown); thus verifying their healthy condition. During the study, the volunteers were monitored in their vital signs. Figure 1 shows that heart rate (50 - 100 beats $/ \mathrm{min})$, blood pressure (50 - 90/84 - $129 \mathrm{mmHg}$ ), breathing frequency $(14-25$ breaths $/ \mathrm{min})$ and otic temperature $\left(36^{\circ} \mathrm{C}\right.$ $-37.8^{\circ} \mathrm{C}$ ) were within normal values through study. In addition, there was no statistical difference in the vital signs due to the treatment as was demonstrated by repeated measures two-way ANOVA.

Plasma concentration-time curves of both formulations show that metformin plasma concentration diminished in a multiexponential mode after peak concentration time (Figure 2). The mean \pm standard deviation of metformin tablets and metformin plus orlistat capsules were $1.39 \pm$ 0.44 and $1.38 \pm 0.48 \mu \mathrm{g} / \mathrm{mL}$ for $\mathrm{Cmax}$; and $7.59 \pm 3.17$ and $7.80 \pm 2.83 \mu \mathrm{g} \mathrm{h} / \mathrm{mL}$ for $\mathrm{AUC}_{24 \mathrm{~h}}$, respectively. These and other pharmacokinetic parameters not considering for determining bioequivalence are shown in Table 2. Analysis of bioequivalence by two one-sided Schuirmann hypothesis test between both metformin formulations showed that $90 \% \mathrm{CI}$ for $\mathrm{Cmax}$ and $\mathrm{AUC}_{24 \mathrm{~h}}$ were within $80 \%$ and $125 \%$ with a probability of exceeding any limit less than 0.05 (Table 3). Furthermore, ANOVA analysis showed that there was no evidence of variability
Table 1. Demographic characteristics of healthy Mexican volunteers subjects. Data are presented as average \pm standard deviation.

\begin{tabular}{ll}
\hline Characteristics & Sample size $(\mathbf{n}=\mathbf{2 6})$ \\
\hline Men & $50.0 \%$ \\
Women & $50.0 \%$ \\
Age (years) & $29.0 \pm 4.9$ \\
Weight $(\mathrm{Kg})$ & $66.1 \pm 10.5$ \\
Waist $(\mathrm{cm})$ & $78.6 \pm 8.0$ \\
Hip (cm) & $91.5 \pm 6.1$ \\
Height (cm) & $162.8 \pm 10.6$ \\
BMI (Kg/m $\left.{ }^{2}\right)$ & $24.8 \pm 1.9$ \\
Waist-hip ratio & $0.84 \pm 0.07$ \\
Waist-to-height ratio & $0.47 \pm 0.03$ \\
\hline
\end{tabular}

for sequence, period or formulation in pharmacokinetic parameters.

\section{Discussion}

The current study was designed to measure all relevant aspects underlying the pharmacokinetics of metformin that may be used to establish the degree of similarity between the two metformin formulations indicated above,
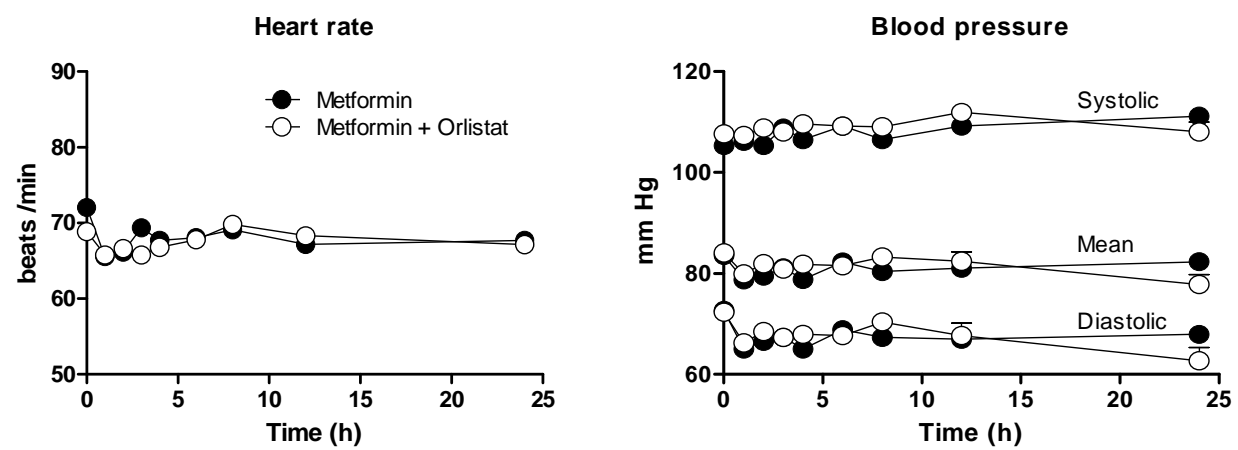

Breathing frequency

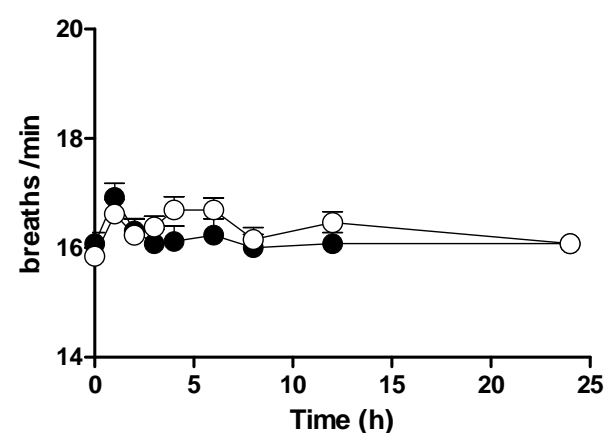

Otic temperature

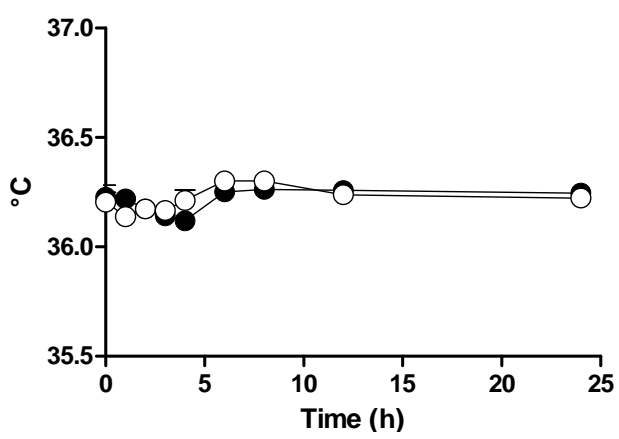

Figure 1. Heart rate, blood pressure, breathing frequency and otic temperature measured after a single-dose of $500 \mathrm{mg}$ metformin or $500 \mathrm{mg}$ metformin plus $60 \mathrm{mg}$ orlistat. Data are presented as mean \pm standard deviation of 26 healthy volunteers. 


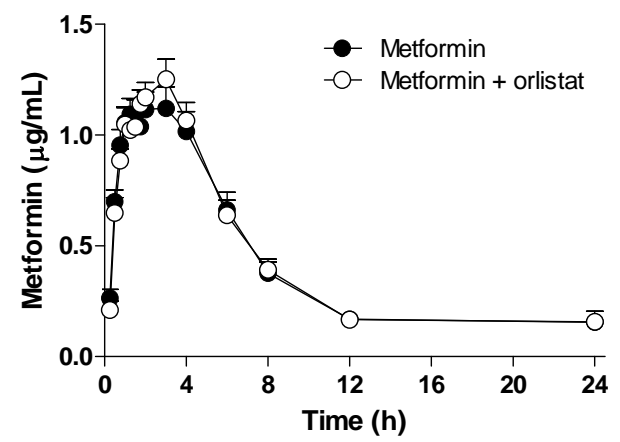

Figure 2. Plasma concentration-time curves of $500 \mathrm{mg}$ metformin alone or combined with $60 \mathrm{mg}$ orlistat in 26 healthy volunteers. Data are presented as mean \pm standard deviation.
Table 2. Pharmacokinetic parameters obtained with tablets of $500 \mathrm{mg}$ metformin alone and combined with $60 \mathrm{mg}$ orlistat after a single-dose administration in 26 healthy Mexican volunteers. Data are presented as average \pm standard deviation. Coefficient of variation in percentage is shown in parenthesis.

\begin{tabular}{ccc}
\hline Parameter & Metformin & Metformin + orlistat \\
\hline $\mathrm{C}_{\max }(\mu \mathrm{g} / \mathrm{mL})$ & $1.39 \pm 0.44(31.4)$ & $1.38 \pm 0.48(34.9)$ \\
$\mathrm{t}_{\max }(\mathrm{h})$ & $2.41 \pm 1.30(53.9)$ & $2.40 \pm 1.08(45.0)$ \\
$\mathrm{AUC}_{24 \mathrm{~h}}(\mu \mathrm{g} \cdot \mathrm{h} / \mathrm{mL})$ & $7.59 \pm 3.17(41.8)$ & $7.80 \pm 2.83(36.3)$ \\
$\mathrm{AUC} \infty(\mu \mathrm{g} \cdot \mathrm{h} / \mathrm{mL})$ & $8.48 \pm 4.13(48.6)$ & $9.13 \pm 4.29(47.0)$ \\
$\mathrm{t}_{1 / 2}(\mathrm{~h})$ & $2.88 \pm 1.46(50.8)$ & $3.52 \pm 2.55(72.5)$ \\
\hline
\end{tabular}

Table 3. Relative bioavailability of metformin combined with orlistat (B) respect to metformin alone (A). Results are given as $\mathbf{9 0 \%}$ confidence intervals for $\mathrm{C}_{\max }$ and area under the curve (AUC). In addition, the table shows the probability to obtain values outside the fixed limits and the power. Limits were fixed within $80 \%-125 \%$.

\begin{tabular}{cccccc}
\hline Parameter & Ratio (B/A) & Confidence intervals (\%) & \multicolumn{2}{c}{ Probability of exceeding any limit } & Power \\
\hline $\mathrm{C}_{\max }(\mu \mathrm{g} / \mathrm{mL})$ & \multirow{2}{*}{0.9776} & $87.5-109.3$ & $\mathrm{p}<80 \%$ & $\mathrm{p}>125 \%$ & 0.9867 \\
$\mathrm{AUC}$ & & & 0.0025 & 0.0004 & $\mathrm{p}<\mathrm{h}$ \\
& \multirow{2}{*}{1.0513} & $88.7-124.7$ & 0.0056 & $0.045 \%$ & 0.7906 \\
\hline
\end{tabular}

and the consequent lack of pharmacokinetic interaction between metfomirn and orlistat. Plasma concentrationtime curves of metformin alone or combined with orlistat overlapped almost perfectly, indicating that orlistat did not modify metformin pharmacokinetic parameters when both drugs are administered together.

In general terms, the magnitude of the absorption of a drug is reflected in the value of the parameter AUC related to the time post-administration. In this regard, the AUC of metformin-orlistat was slightly higher than metformin, notwithstanding; values were not statistically different and the small arithmetic differences could be even due to pharmaceutical presentation more than combination. Pharmacokinetic results obtained in the current study showed conclusive data with respect to therapeutic equivalence since the comparison between the test formulation (metformin-orlistat) and the reference formulation (metformin) for $\mathrm{Cmax}$ and $\mathrm{AUC}_{24 \mathrm{~h}}$ showed percentages that fall in the rank of equivalence. These pharmacokinetic parameters are according to those reported in previous studies [14-19].

During the study, 7 mild adverse effects were presented, 3 abdominal colic, 3 abdominal distensions and 1 cephalea, such effects have been reported as common with both drugs $[28,29]$. In addition, a previous comparative study, in which was added during 4 months metformin tablets to half of the obese patients treated with orlistat capsules, showed that both therapies were well tolerated and no subject discontinued therapy since ad- verse events were mild and transient [30]. A 1-year multicenter trial tested placebo or orlistat in overweight and obese patients who are being treated with metformin, in that study, the placebo treatment evoked less adverse effects than orlistat treatment $(4.6 \%$ vs. $9.8 \%$, respectively). However, orlistat treatment had less premature withdrawal due treatment refusal, loss to follow-up, protocol violations or treatment failure. Furthermore, orlistat group produced a greater weight loss, improved glycemic control and decreased total cholesterol, LDL cholesterol and systolic blood pressure; suggesting that orlistat is a useful adjunctive treatment of metformin for producing weight loss and improving glycemic control, serum lipid levels, and blood pressure in obese patients with type 2 diabetes [31].

In summary, according to the evidence, we conclude that there is no pharmacokinetic interaction between metformin and orlistat. Moreover, previous studies suggest that combination metformin-orlistat could be a safety formulation and a more effective treatment than monotherapy. For this reason, we recommend for clinical usage the administration of metformin-orlistat capsules as a treatment that would improve the pharmacological adherence in obese patients with T2DM.

\section{REFERENCES}

[1] World Health Organization, "Media Centre, Diabetes, Fact Sheet N 312,” August 2011. 
http:/www.who.int/mediacentre/factsheets/fs312/en/inde x.html

[2] J. E. Shaw, R. A. Sicree and P. Z. Zimmet, "Global Estimates of the Prevalence of Diabetes for 2010 and 2030," Diabetes Research and Clinical Practice, Vol. 87, No. 7, 2010, pp 4-14.

[3] Secretaría de Salubridad y Asistencia, "Bases Técnicas del Acuerdo Nacional para la Salud Alimentaria, Estrategia Contra el Sobrepeso y la Obesidad," 1st Edition, Subdirección de Comunicación Científica y Publicaciones del Instituto Nacional de Salud Pública, México, 2010.

[4] S. Braun, K. Bitton-Worms and D. Leroith. "The Link between the Metabolic Syndrome and Cancer," International Journal of Biological Sciences, Vol. 7, No. 7, 2011, pp. 1003-1015.

[5] E. Kassi, P. Pervanidou, G. Kaltsas and G. Chrousos, "Metabolic Syndrome: Definitions and Controversies," BMC Medicine, Vol. 9, 2011, p. 48.

[6] R. J. Rodríguez-Kú, "Metabolicsyndrome and Cerebrovascular Disease: Evidence in Their Treatment," Revista de Neurología, Vol. 48, No. 5, 2009, pp. 255-260.

[7] S. Mottillo, K. B. Filion, J. Genest, L. Joseph, L. Pilote, P. Poirier, S. Rinfret, E. L. Schiffrin and M. J. Eisenberg, "The Metabolic Syndrome and Cardiovascular Risk a Systematic Review and Meta-Analysis," Journal of the American College of Cardiology, Vol. 56, No. 14, 2010, pp. 1113-1132. doi:10.1016/j.jacc.2010.05.034

[8] D. C. Lau, "Diabetes and Weight Management," Primary Care Diabetes, Suppl. 1, 2010, pp. S24-S30. doi:10.1016/S1751-9918(10)60006-X

[9] L. B. Lorenz and R. A. Wild, "Polycystic Ovarian Syndrome: An Evidence-Based Approach to Evaluation and Management of Diabetes and Cardiovascular Risks for Today's Clinician," Clinical Obstetrics and Gynecology, Vol. 50, No. 1, 2007, pp. 226-243. doi:10.1097/GRF.0b013e31802f5197

[10] R. P. Troiano, E. A. Frongillo Jr., J. Sobal and D. A. Levitsky, "The Relationship between Body Weight and Mortality: A Quantitative Analysis of Combined Information from Existing Studies," International Journal of Obesity, Vol. 20, No. 1, 1996, pp. 63-75.

[11] Y. D. Kim, K. G. Park, Y. S. Lee, Y. Y. Park, D. K. Kim, B. Nedumaran, W. G. Jang, W. J. Cho, J. Ha, I. K. Lee, C. H. Lee and H. S. Choi, "Metformin Inhibits Hepatic Gluconeogenesis through AMP-Activated Protein Kinase-Dependent Regulation of the Orphan Nuclear Receptor SHP," Diabetes, Vol. 57, No. 2, 2008, pp. 306314. doi: $10.2337 / \mathrm{db} 07-0381$

[12] K. Niswender, "Diabetes and Obesity: Therapeutic Targeting and Risk Reduction-A Complex Interplay," Diabetes, Obesity and Metabolism, Vol. 12, No. 4, 2010, pp. 267-287. doi:10.1111/j.1463-1326.2009.01175.x

[13] C. J. Glueck, R. N. Fontaine, P. Wang, M. T. Subbiah, K. Weber, E. Illig, P. Streicher, L. Sieve-Smith, T. M. Tracy, J. E. Lang and P. McCullough, "Metformin Reduces Weight, Centripetal Obesity, Insulin, Leptin, and LowDensity Lipoprotein Cholesterol in Nondiabetic, Mor- bidly Obese Subjects with Body Mass Index Greater than 30," Metabolism, Vol. 50, No. 7, 2001, pp. 856-861. doi:10.1053/meta.2001.24192

[14] G. T. Tucker, C. Casey, P. J. Phillips, H. Connor, J. D. Ward and H. F. Woods, "Metformin Kinetics in Healthy Subjects and in Patients with Diabetes Mellitus," British Journal of Clinical Pharmacology, Vol. 12, No. 2, 1981, pp. 235-246.

[15] N. C. Sambol, J. Chiang, M. O’Conner, C. Y. Liu, E. T. Lin, A. M. Goodman, L. Z. Benet and J. H. Karam, "Pharmacokinetics and Pharmacodynamics of Metformin in Healthy Subjects and Patients with Noninsulin-Dependent Diabetes Mellitus," Journal of Clinical Pharmacology, Vol. 36, No. 11, 1996, pp. 1012-1021. doi: $10.1177 / 009127009603601105$

[16] A. J. Scheen, "Clinical Pharmacokinetics of Metformin," Clin Pharmacokinet, Vol. 30, No. 5, 1996, pp. 359-371. doi:10.2165/00003088-199630050-00003

[17] D. Bhavesh, G. Chetan, K. M. Bhat and Shivprakash, "Estimation and Pharmacokinetics of Metformin in Human Volunteers," Indian Journal of Pharmaceutical Education and Research, Vol. 41, No. 2, 2007, pp. 139139.

[18] S. Al Hawari, E. AlGaai, A. Yusuf, A. Abdelgaleel and M. M. Hammami, "Bioequivalence Study of Two Metformin Formulations," Arzneimittelforschung, Vol. 57, No. 4, 2007, pp. 192-195.

[19] G. G. Graham, J. Punt, M. Arora, R. O. Day, M. P. Doogue, J. K. Duong, T. J. Furlong, J. R. Greenfield, L. C. Greenup, C. M. Kirkpatrick, J. E. Ray, P. Timmins and K. M. Williams, "Clinical Pharmacokinetics of Metformin," Clinical Pharmacokinetics, Vol. 50, No. 2, 2011, pp. 81-98. doi:10.2165/11534750-000000000-00000

[20] R. Padwal, S. K. Li and D. C. Lau, "Long-Term Pharmacotherapy for Overweight and Obesity: A Systematic Review and Meta-Analysis of Randomized Controlled Trials," International Journal of Obesity, Vol. 27, 2003, pp. 1437-1446. doi:10.1038/sj.ijo.0802475

[21] R. S. Padwal and S. R. Majumdar, "Drug Treatments for Obesity: Orlistat, Sibutramine, and Rimonabant," Lancet, Vol. 369, 2007, pp. 71-77. doi:10.1016/S0140-6736(07)60033-6

[22] J. M. Miles, L. Leiter, P. Hollander, T. Wadden, J. W. Anderson, M. Doyle, J. Foreyt, L. Aronne and S. Klein, "Effect of Orlistat in Overweight and Obese Patients with Type 2 Diabetes Treated with Metformin," Diabetes Care, Vol. 25, No. 7, 2002, pp. 1123-1128. doi:10.2337/diacare.25.7.1123

[23] R. Sari, M. K. Balci, F. Coban and G. Yazicioglu, "Comparison of the Effect of Orlistat vs Orlistat plus Metformin on Weight Loss and Insulin Resistance in Obese Women," International Journal of Obesity, Vol. 28, No. 8, 2004, pp. 1059-1063. doi:10.1038/sj.ijo.0802707

[24] E. Souri, H. Jalalizadeh, A. Kebriaee-Zadeh and B. Zadehvakili, "HPLC Analysis of Orlistat and Its Application to Drug Quality Control Studies," Chemical \& Pharmaceutical Bulletin, Vol. 55, No. 2, 2007, pp. 251- 


\section{4. doi: $10.1248 / \mathrm{cpb} .55 .251$}

[25] S. C. Chow, H. Wang, "On Sample Size Calculation in Bioequivalence Trials," Journal of Pharmacokinet Pharmacodyn, Vol. 28, No. 2, 2001, pp. 155-169. doi:10.1023/A:1011503032353

[26] M. Rowland and T. N. Tozer, "Clinical Pharmacokinetics. Concepts and Applications," 3rd Edition, Lea \& Febiger, Philadelphia, London, 1995.

[27] D. J. Schuirmann, "A Comparison of the Two One-Sided Tests Procedure and the Power Approach for Assessing the Equivalence of Average Bioavailability," Journal of Pharmacokinetics and Biopharmaceutics, Vol. 15, No. 6, 1987, pp. 657-680. doi:10.1007/BF01068419

[28] S. S. Jain, S. J. Ramanand, J. B. Ramanand, P. B. Akat, M. H. Patwardhan and S. R. Joshi, "Evaluation of Efficacy and Safety of Orlistat in Obese Patients," Indian Journal of Endocrinology and Metabolism, Vol. 15, No. 2, 2011, pp. 99-104. doi:10.4103/2230-8210.81938
[29] R. A. DeFronzo and A. M. Goodman, "Efficacy of Metformin in Patients with Non-Insulin-Dependent Diabetes Mellitus. The Multicenter Metformin Study Group," New England Journal of Medicine, Vol. 333, No. 9, 1995, pp. 541-549. doi:10.1056/NEJM199508313330902

[30] R. Sari, M. K. Balci, E. Coban and G. Yazicioglu, "Comparison of the Effect of Orlistat vs Orlistat plus Metformin on Weight Loss and Insulin Resistance in Obese Women," International Journal of Obesity, Vol. 28, No. 8, 2004, pp. 1059-1063. doi:10.1038/sj.ijo.0802707

[31] J. M. Miles, L. Leiter, P. Hollander, T. Wadden, J. W. Anderson, M. Doyle, J. Foreyt, L. Aronne and S. Klein, "Effect of Orlistat in Overweight and Obese Patients with Type 2 Diabetes Treated with Metformin," Diabetes Care, Vol. 25, No. 7, 2002, pp. 1123-1128. doi: $10.2337 /$ diacare.25.7.1123 